\title{
DEFESA DA CONCORRÊNCIA E \\ REGULAÇÃO ECONÔMICA NO BRASIL
}

FREE MARKET DEFENSE AND ECONOMIC REGULATION

IN BRAZIL

JOSÉ MATIAS-PEREIRA

Economista e advogado. Professor pequisador e ex-coordenador do programa de pós-graduação em Administração da Universidade de Brasília (2002/2004). Doutor em Ciência Política pela Universidade Complutense de Madri, Espanha. Autor de Finanças públicas: a política orçamentária no Brasil, 2. ed., São Paulo, Atlas, 2003. Foi conselheiro do Conselho Administrativo de Defesa Econômica (Cade) por dois mandatos (1992-1994 e 1994-1996). Quadra 5, Conjunto 1, Casa 9SMPW - Brasília - DF - CEP 71735-050

E-mail:matias@unb.br 


\section{RESUMO}

O Estado, para cumprir adequadamente suas funções, pode divulgar e utilizar as informações sinalizadoras dos agentes (NORTH, I990), bem como acelerar o processo de mudanças e adequações institucionais, buscando adaptar normas e leis à realidade mutante da sociedade. Assim, numa economia de mercado como a brasileira, o governo necessita contar com dois importantes instrumentos - que interagem e se complementam -, para buscar o adequado funcionamento dos mercados: a legislação antitruste e a política de regulação econômica. Este artigo tem o objetivo de retratar em linhas gerais a política e o sistema de defesa da concorrência no Brasil, bem como analisar os impactos das decisões do Conselho Administrativo de Defesa Econômica (Cade), para o fortalecimento institucional do sistema de defesa da concorrência no Brasil, a partir da abertura da economia brasileira na década de I990, com destaque para as decisões sobre os atos de concentração analisados pós-I994. Concluímos que o sistema de defesa da concorrência - em que pese ainda estar em construção, e necessitar de maior celeridade na apreciação de determinados atos e aperfeiçoar o mecanismo de coordenação dos órgãos do sistema -, está se consolidando institucionalmente no Brasil.

\section{PALAVRAS-CHAVE}

Defesa da concorrência; Mercado concorrencial; Ato de concentração; Brasil.

\section{A B STRACT}

The State, to fulfill its functions adequately, can divulge and use the information of the agents (NORTH, I990), as well as speeding up the institutional process of changes and adequacies, searching to adapt norms and laws to the mutant reality of the society. Thus, in a market economy as the Brazilian, the government needs to count on two important instruments - that they interact and if they complement - to search the adequate functioning of the markets: the antitrust legislation and the politics of economic regulation. This article has the objective to portray in general lines the politics and the system of free market defense in Brazil, as well as analyzing the impacts of the decisions of the Board of directors of CADE, for the institutional forty of the system of free market defense in Brazil, from the opening of the Brazilian 
economy in the Nineties of the century passed, with prominence for the decisions on the analyzed acts of concentration after-I994. We conclude that the system of free market defense - where it still weighs to be in construction, and to need a bigger rapidity in the appreciation of determined acts and to perfect the mechanism of coordination of the agencies of the system -, it is if consolidating institutional in Brazil.

\section{KEYWORDS}

Free market defense; Competition market; Concentration act; Brazil.

\section{INTRODU ÇÃO}

Para cumprir adequadamente suas funções, o Estado pode divulgar e utilizar as informações sinalizadoras dos agentes (NORTH, I990), bem como acelerar o processo de mudanças e adequações institucionais, buscando adaptar normas e leis à realidade mutante da sociedade. Esse é o caso, por exemplo, dos esforços desenvolvidos nos últimos dez anos para estruturar e consolidar o sistema de defesa da concorrência no Brasil e, de maneira especial, do Conselho Administrativo de Defesa Econômica (Cade).

No Brasil, a importância das políticas de defesa da concorrência surge no contexto das mudanças do papel do Estado, no início dos anos 9o, quando esse avançou na privatização das empresas estatais, se afastando de sua função de Estado empresário (FARINA e AZEVEDO, 200I). É oportuno lembrar que, nas décadas de 1970 e I980, fora consolidada uma economia apoiada em larga medida nas grandes empresas estatais. Essa situação permitiu que o Estado se transformasse num fornecedor privilegiado de bens e serviços para o consumidor e garantidor de produtos e serviços pela iniciativa privada. Dessa forma, o Estado empresário consolidou-se e, em muitos casos, se sobrepôs à própria administração pública direta. A reconhecida importância das decisões que eram adotadas pela Comissão Interministerial de Preços (CIP), nesse período, decorre dessas disfunções econômicas, que geraram uma degeneração no sistema concorrencial do país. Verificase, assim, que a economia brasileira se apoiava, no final da década de I980, nas grandes empresas estatais e na estrutura cartelizada do setor bancário.

À medida que o Estado passou a privilegiar sua função de regulador, o Cade ganhou maior dimensão. A nova realidade econômica e a promulgação da Lei no 8.884, de 1994, criaram as condições para garantir a defesa da concorrência no país (SALGADO, I997). Buscava-se evitar que as empresas abusassem de suas posições dominantes, impondo restrições à competição nos mercados em que atuavam ou ainda incrementassem seu poder de mercado por meio de alianças 
ou fusões com empresas concorrentes. Assim, as políticas de defesa da concorrência, além de coibirem que as barreiras suprimidas pelo governo fossem recompostas pelos agentes com elevado nível de poder econômico, propuseramse criar uma cultura concorrencial entre produtores e consumidores em que as normas de competição passaram a ser necessárias para garantir a própria existência do mercado (CONSIDERA e ARAÚJO, 2002).

A regulação de setores específicos na economia teve como propósito corrigir eventuais falhas de mercado. A regulação do mercado, especialmente em setores em que a estrutura do mercado apresenta elevado grau de concentração - visto que concentrar é restringir o espaço de mercado livre -, é condição indispensável para garantir um adequado ambiente concorrencial. Essa interferência do Estado na organização da economia intensificou-se no mundo com os danos causados pelas grandes concentrações, notadamente diante da possibilidade de ocorrerem também danos potenciais. A concentração deve ser vista como uma ação que, mesmo quando não inviabiliza a concorrência, altera o nível de competição, prejudicando em última instância o consumidor.

Observa-se que o mercado se apresenta como um instrumento indispensável para atender as demandas materiais do ser humano, visto que atua como poupador de recursos e tempo, na medida em que permite a troca entre pessoas de uma maneira impessoal. Os mercados são instituições humanas que funcionam apoiadas num conjunto de regras sociais que variam no tempo e no espaço. Assim, o mercado para cumprir sua função, como as demais instituições humanas, necessita que determinadas normas sejam preservadas, entre as quais destacamos duas: a liberdade de concorrer no mercado e a autonomia de escolha do consumidor. Para que ocorra o funcionamento adequado do mercado é preciso que o Estado disponha de instituições de salvaguarda sólidas na área de defesa da concorrência (MATIAS-PEREIRA, 2003).

\subsection{FORMULAÇÃO DA PERGUNTA MOTIVADORA E OBJETIVOS}

A regra desejada do mercado é a concorrência. O esforço, entretanto, que as empresas desenvolvem para sobreviver num ambiente freqüentemente hostil, conforme descrito por Schumpeter em sua obra Theory of economic development (I9I2), tende a gerar, em muitos casos, algum tipo de restrição à atuação e à entrada de novos concorrentes no mercado. Nesse sentido, o Estado, conforme observado nos países desenvolvidos, tem a responsabilidade de atuar como garantidor da "cidadania econômica" (OCDE, I992).

Nos países em desenvolvimento, com pequena tradição em defesa da concorrência, é comum haver injunções políticas e empresariais para evitar e/ou rever as decisões dos órgãos de defesa da concorrência. Esse fenômeno também se verifica 
no Brasil, onde as decisões do Cade não são aceitas pacificamente pelas lideranças políticas e empresariais afetadas pelas decisões do órgão. Argumenta-se que as pressões que questionam a decisão e a própria existência do Cade podem ser creditadas, entre outros aspectos, à carência de uma cultura no campo da defesa da concorrência, agravada em particular pelo desconhecimento, por parte das lideranças políticas e empresariais, de que o objetivo maior da defesa da concorrência é definir se determinada operação entre agentes econômicos ou a prática restritiva à concorrência estão produzindo efeitos indesejáveis no mercado analisado.

Essas evidências indicam que o "sistema de defesa da concorrência no Brasil" - que ainda está em construção - encontra-se frágil institucionalmente, o que vem se refletindo em sua capacidade de assegurar a aplicação das regras de concorrência no país, em conformidade com o princípio da economia de mercado e da livre concorrência. Diante dessas questões, formulamos a seguinte pergunta: "As decisões adotadas no âmbito do Cade, nos últimos ıo anos, no sentido de vetar as aquisições de empresas que elevariam a concentração no mercado, estão contribuindo para a consolidação institucional do sistema de defesa da concorrência no Brasil?"

O objetivo principal neste artigo, a partir dessa pergunta, é retratar, em linhas gerais, a política e o sistema de defesa da concorrência no Brasil, bem como analisar se as decisões do Cade - a partir da promulgação da legislação antitruste de 1994 - estão contribuindo para o fortalecimento institucional do sistema de defesa da concorrência no Brasil.

\section{3 DEFINIÇÃO DOS CONCEITOS UTILIZADOS}

Os conceitos relacionados à defesa da concorrência, citados a seguir, foram retirados do Glossário Básico de Defesa da Concorrência (MF, 2004).

Ordem econômica deve ser entendida como um conjunto de princípios estabelecidos pela Constituição Federal do Brasil em seu título VII (artigos I70 a I92), e que tem por objetivo fixar os parâmetros da atividade econômica, coordenando a atuação dos diversos sujeitos que põem em prática aquela mesma atividade. A predominância de uma economia social de mercado - que valoriza o capitalismo democrático - enfatiza o direito de propriedade individual e sua conseqüência inarredável: o princípio da liberdade de iniciativa como fatores indispensáveis para o progresso e o impulso da atividade econômica. Defendem-se, porém, ao mesmo tempo, os princípios da função social da propriedade, da livre concorrência, de respeito aos direitos dos consumidores e dos trabalhadores. Propugnase pela presença regulamentadora do Estado, predominantemente, e também por uma presença atuante nos casos em que a lei especifica como necessários. 
Agente econômico deve ser entendido como qualquer pessoa física ou jurídica (empresa privada ou pública, com fins lucrativos ou não, indústria, comércio, profissional liberal etc.) que participa, independentemente, como sujeito ativo na atividade econômica.

Regulação econômica refere-se a políticas com que o Governo controla preços como tarifas públicas e/ou decide regras de participação e atuação no mercado.

Defesa da concorrência refere-se a políticas que definem determinados comportamentos das empresas como sendo ilegais, por prejudicarem outras empresas, os consumidores e/ou diminuírem o bem-estar social.

Custos de transação são os gastos associados às transações entre agentes econômicos que não se expressam explicitamente nos preços acordados entre as partes, sendo exemplo o custo de elaborar e aplicar um contrato.

Controle de concentrações é uma das vertentes de atuação do Sistema Brasileiro de Defesa da Concorrência (SBDC). O Cade, balizado pelos pareceres da SDE [Secretaria de Direito Econômico] e da SEAE [Secretaria de Acompanhamento Econômico], aprecia se determinada concentração de empresas pode causar efeitos danosos à concorrência.

Os atos de concentração têm, potencialmente, efeitos negativos e positivos sobre o bem-estar econômico. Os efeitos negativos decorrem de um eventual exercício de poder de mercado pela empresa concentrada - aumento abusivo de preços, fundamentalmente -, enquanto os efeitos positivos derivam de economias de escala e de redução de custos de transação, entre outros, que podem proporcionar vantagens competitivas para as empresas participantes. A esse respeito, veja-se a definição legal no $\ 3^{\circ}$ do artigo 54 da Lei no $8.884 / 94$.

Conglomeração é a concentração que envolve agentes econômicos distintos, que ofertam produtos ou serviços distintos, que podem ou não ser complementares entre si, mas que não necessariamente fazem parte da mesma cadeia produtiva. Genericamente, uma conglomeração é saudável à competição, pois significa a "entrada" de uma empresa em um determinado mercado de produto ou serviço. No entanto, uma conglomeração pode ter efeitos nocivos à concorrência quando houver complementaridade entre os produtos ou serviços envolvidos. [Por isso não se pode afirmar como acima que os conglomerados não fazem parte de uma mesma cadeia.]

Concentração horizontal envolve agentes econômicos distintos e competidores entre si, que ofertam o mesmo produto ou serviço em um determinado mercado relevante. A concentração (ou integração) vertical envolve agentes econômicos distintos, que ofertam produtos ou serviços distintos e que fazem parte da mesma cadeia produtiva. 
Condutas oportunistas são condutas verificadas quando uma parte envolvida em determinado contrato procura aproveitar-se, às custas da outra parte, do processo de renegociação do referido contrato.

Dados esses conceitos, focaremos os aspectos conceituais e teóricos mais relevantes, bem como destacaremos como a teoria econômica pode ser usada para aumentar a consistência das análises que envolvem os atos de concentração.

\section{REFERENCIAL TEÓRICO}

Sem embargo, é inegável que as leis de defesa da concorrência devem sua existência à teoria econômica. Sustentam Kwoka e White (I999) que a revolução na política antitruste norte-americana, nas últimas duas décadas, é resultado da aplicação da teoria econômica no debate judicial dessa área. A teoria aplicada ao estudo das organizações, focalizando a análise microeconômica, que foi desenvolvida por Williamson (I985) em seu livro The economic institutions of capitalism - apoiado nas contribuições de Coase, Arrow, Simon e de MacNeil -, utiliza dois pressupostos comportamentais básicos: o da racionalidade limitada de Simon (I972) e o seu corolário, os contratos incompletos, que, associados ao pressuposto do oportunismo, fornecem as bases para a análise das formas de governança das organizações. A contribuição de North (I990), que se concentra na análise macroeconômica, também deriva da influência de Coase (I988), mas diferenciase do trabalho de Williamson (I985), por priorizar o papel das instituições econômicas, seu desenvolvimento e sua relação com as organizações. North (I990) define as instituições como o conjunto de leis, normas, costumes, tradições e outros aspectos culturais que balizam a ação de sociedades, organizações e indivíduos. Para esse autor, é de fundamental importância o papel das instituições como redutoras dos custos de transação para a sociedade.

O neo-institucionalismo, torna-se relevante ressaltar, enfoca as estruturas de poder de uma dupla perspectiva: a organização e o controle do sistema econômico e o processo jurídico, ou seja, o nexo entre marco jurídico-processo econômico, que é o processo central que organiza a estrutura da relação jurídico-governopolítica-economia. Na análise da evolução das principais relações e influências das escolas do pensamento econômico, constataremos que os antecedentes do neo-institucionalismo são bastante remotos, visto que suas origens se localizam nos estudos dos economistas clássicos, no historicismo alemão, na escola austríaca e no marxismo, com destaque para Adam Smith, John Stuart Mill e Karl Marx (HODGSON, I996). 
Privilegiaremos em nossa análise distintos autores, por exemplo, Kwoka e White (I999); Posner (I998); Macneil (I974, I978); Kahn (I988); Dahl e Lindblom (I992); Coase (I937, I988); Ross (I973, I993); Kaplan (I980); Farina (I996); Possas et al. (I995); Sullivan e Harrison (I988). Em particular, daremos especial atenção às vertentes que compõem a denominada "Nova Economia Institucional": a economia dos custos de transação de Williamson (1985, 1996); a teoria de evolução institucional de North (1984, I990); além dos autores da vertente que cuida das "instituições e desempenho econômico", como Olson (I982), North (I990) e Stiglitz et al. (I990), por entenderem que as instituições têm papel decisivo na dinâmica e no desenvolvimento de qualquer sistema econômico. Por meio delas é possível explicar o êxito ou fracasso, o crescimento ou a estagnação de um sistema socioeconômico. Assim, as instituições (formais e informais) definem o marco de restrições legais e extralegais (econômicas, sociais e culturais etc.) no meio das quais os indivíduos atuam, se organizam e promovem intercâmbios.

\section{1 ECONOMIA E PRÁTICA ANTITRUSTE}

A economia e a prática antitruste, nos últimos vinte anos, passaram por uma série de transformações que introduziram, de forma crescente, argumentos de eficiência econômica, sobretudo de caráter produtivo, como justificativa para atos de concentração e determinadas condutas empresariais (KWOKA e WHITE, I999). Como resultado, os órgãos de defesa da concorrência em diversos países passaram a avaliar não somente os efeitos anticompetitivos, como na antiga tradição, mas também os potenciais impactos em termos de ganhos de eficiência econômica quando do julgamento de condutas horizontais e verticais, fusões, aquisições e joint ventures entre empresas (BRAULT, I995).

A justificativa teórica mais relevante, no campo da economia, em que pese não ser a única, para a regulação encontra-se no argumento do monopólio natural. As mudanças tecnológicas, por sua vez, reduziram a importância das economias de escala na determinação de tamanhos mínimos eficientes de planta, desafiando a existência de um significativo trade-off entre eficiência produtiva e alocativa, rationale econômica da regulação dos monopólios naturais. Assim, a preocupação de caracterizar tecnicamente a existência de monopólio natural em determinado setor deixou de ser relevante. O que passou a ser relevante foi o esforço de se comprovar se os ganhos de eficiência e custos derivados da escala monopolística são suficientes para compensar os custos e riscos da regulação. 


\subsection{POLÍTICAS DE DEFESA DA CONCORRÊNCIA NO ENFOQUE TRADICIONAL}

A política de defesa da concorrência está tradicionalmente apoiada na teoria de organização industrial - desenvolvida a partir dos anos 50 pela "Escola de Harvard" -, em que a estrutura da empresa, traduzida no número de produtores e compradores, diferenciação do produto, barreiras à entrada, estruturas de custos, integração vertical e diversificação, determinaria sua conduta, ou seja, na definição de políticas de preços, $\mathrm{P} \& \mathrm{D}$, estratégia e investimento, e esta, o seu desempenho - alocação eficiente dos recursos, satisfação aos consumidores, progresso técnico, eqüidade de renda, entre outros. Dessa forma, toda concentração de mercado seria ineficiente. Esse enfoque criou o denominado paradigma "estrutura-conduta-desempenho".

$\mathrm{Na}$ atualidade, a literatura econômica vem dando destaque a uma nova visão, que incorporou em suas análises o conceito de eficiência. Assim, da análise per se, ou seja, restrição a qualquer ato de concentração, evoluiu-se para a utilização da regra da razoabilidade, segundo a qual um ato de concentração pode ser aceito, desde que implique ganhos de eficiência. A partir dessa percepção, buscamos apresentar, a seguir, as proposições normativas mais relevantes desse enfoque, que procura levar em consideração a "eficiência" que pode reduzir os efeitos negativos provocados por configurações de mercado mais concentrado.

\subsection{REGULAÇÃO SETORIAL, DEFESA DA CONCORRÊNCIA E PARÂMETROS REGULATÓRIOS DO ESTADO}

A regulação setorial e a defesa da concorrência nas economias de mercado estão entre as principais funções que o Estado desempenha e se apresentam como uma atividade da maior importância para as empresas e para a economia em geral. Muitas empresas atuam em mercados sujeitos a regulação setorial específica, com implicações decisivas em sua atividade, que podem ir desde as formas de organização empresarial às estratégias de preços e investimentos (KAHN, I988). As empresas, em outros casos, em decorrência da posição relevante que detêm nos mercados em que atuam, necessitam dispensar especial atenção às regras de defesa da concorrência, em áreas como as de preços, descontos, compras de bens e serviços, bem como nas operações de concentração em que se envolvem. A regulação e a defesa da concorrência, dessa forma, são indispensáveis para uma economia de mercado saudável e competitiva, com repercussões em todos os setores de atividade econômica. 
No que se refere à Administração Pública, a regulação se apresenta como um grande desafio, visto que está relacionada com a própria modernização do Estado na atualidade, pelas mudanças na forma e no conteúdo de suas relações com as empresas e o público em geral (CONSIDERA e ALBUQUERQUE, 200I). A regulação é um processo que envolve a análise e o diagnóstico dos problemas, o estudo de possibilidades de atuação e a fundamentação das decisões tomadas, em matérias de grande exigência técnica. Assim, torna-se evidente que a formação de competências nas áreas de economia da regulação e da concorrência representa um fator indispensável na atividade empresarial e em diferentes áreas da Administração Pública.

A forma peculiar pela qual as políticas e os sistemas de defesa da concorrência enfrentam essas questões varia de país para país, embora várias semelhanças possam ser observadas, sobretudo no que diz respeito ao objetivo básico da legislação antitruste de exercer algum tipo de controle sobre atos de concentração e sobre as condutas das empresas que detêm poder de mercado (BRAULT, I995). Podem-se perceber, para cada área de aplicação das políticas de defesa da concorrência, determinadas linhas orientadoras no que se refere à concepção econômica que as baliza. A esse respeito, veja o trabalho de Posner (I998), que aborda a análise econômica do direito.

\subsection{O CRITÉRIO DE ANÁLISE ANTITRUSTE DE ATOS DE CONCENTRAÇÃO}

A presunção de que uma operação gere acréscimo de poder de mercado e efeitos anticompetitivos, na linha das proposições do enfoque estruturalista de organização industrial, decorre da avaliação de que o grau de concentração do mercado relevante, seguindo as proposições do enfoque estruturalista de organização industrial, é alto e será elevado ainda mais pela operação em análise, em um contexto no qual a intensidade da concorrência potencial é baixa - ainda que outros elementos também possam ser levados em conta.

Assim, na análise antitruste de atos de concentração de natureza horizontal utiliza-se o seguinte critério: (i) estimativas das participações das empresas no mercado relevante; (ii) avaliação do nível das barreiras à entrada; e (iii) exame das eficiências econômicas geradas pela operação. As operações que implicam aumento considerável do grau de concentração em mercados caracterizados por elevado nível de barreiras à entrada e baixo dinamismo tecnológico, por não apresentarem evidências da geração de ganhos de eficiência produtiva significativos, não costumam ser autorizadas pelas autoridades antitrustes. 
Observa-se, quanto à medição do aumento do nível de concentração, que a delimitação das dimensões do mercado é feita por um instrumento conceitual específico à análise econômica no âmbito da defesa da concorrência, incorporando simultaneamente os aspectos da elasticidade da oferta e da demanda. Dessa forma, o "mercado relevante" de uma operação é definido como aquele no qual, em uma situação hipotética, um eventual monopolista poderia exercer seu poder de mercado, elevando preços e auferindo lucros extraordinários (POSSAS, I996).

No tocante ao grau de concentração, podemos verificar que esse é mensurado por indicadores tais como a participação de mercado das quatro maiores firmas (CR4) ou o índice Herfindahl-Hirschman (HHI), calculado por meio da soma dos quadrados dos market shares individuais das firmas participantes do mercado relevante.

Em relação à concorrência potencial, a análise das condições de entrada é usualmente realizada levando-se em conta as quatro fontes de barreiras à instalação de novos concorrentes propostas originalmente por Bain (I956), englobando a diferenciação de produtos, as vantagens absolutas de custo, as economias de escala e os requerimentos de investimentos iniciais elevados.

Por fim, busca-se avaliar em que medida as eficiências econômicas - cujas raízes, em geral, têm origem, segundo as visões tradicionais, nas características da tecnologia, tais como economias de escala e de escopo -, eventualmente geradas pela operação, podem contrabalançar os efeitos anticompetitivos, derivados do aumento de poder de mercado, por sua vez pressupostos a partir do incremento do grau de concentração e manifestos num suposto futuro aumento de preços, que reduz o excedente do consumidor.

As fusões ou aquisições conglomeradas - isto é, realizadas entre empresas situadas em mercados relevantes distintos - são vistas como potencialmente anticompetitivas à luz das teorias da concorrência potencial, em suas duas vertentes, a teoria do "entrante potencial percebido" (perceived potential entrant) e a do "entrante potencial efetivo" (actual potential entrant).

Na primeira delas, os possíveis efeitos anticompetitivos de uma operação de aquisição, fusão ou associação entre uma empresa já instalada no mercado e um entrante potencial resultam de uma redução da ameaça de entrada que estaria impedindo uma elevação de preços e margens. Já na segunda, supõe-se que um processo de entrada já estaria em vias de ser desencadeado pelo competidor potencial participante da operação, de modo que essa evita que uma estrutura de mercado mais desconcentrada - e supostamente mais competitiva - se configure no futuro próximo (ROSS, I993; KAPLAN, I980). 


\section{AVALIACC̃O DO SISTEMA DE DEFESA DA CONCORRÊNCIA DO BRASIL}

Utilizamos a pesquisa Rating Enforcement: Our Annual Ranking of the World's 27 Senior Competition Regimes, 2003, publicada em 2004 pela Global Competition Review (GCR) (www.globalcompetitionreview.com/news/frontpage.cfm) como referência - tendo em vista as limitações das avaliações nacionais na área de defesa da concorrência no Brasil - para apoiar algumas de nossas argumentações.

Trata-se de uma classificação (em que pesem as eventuais restrições, especialmente dos órgãos que se encontram numa posição desfavorável) que está apoiada em parâmetros objetivos e entrevistas feitas com advogados de várias partes do mundo. Os entrevistados opinam sobre as agências de seu país e de outros, ou seja, a avaliação brasileira foi feita por advogados brasileiros e de alguns outros países. Esse método, por si só, pode resultar em algumas distorções, visto que é possível que advogados de outras nacionalidades escondam as falhas das agências de seus respectivos países.

A GCR busca obter dados sobre as agências: número de funcionários, orçamento e número total de casos (dividindo-os em atos de concentração, cartéis, abusos de posição dominante e outros). Com vistas a uma possível comparação entre a estrutura das agências norte-americanas e do Brasil, podemos observar que a Federal Trade Commission (FTC) conta com mais de mil funcionários para examinar menos de 300 casos por ano, dos quais cerca de 220 são atos de concentração. Já o Department of Justice (DoJ) tem 400 funcionários para cerca de 280 casos anualmente, dos quais I75 são atos de concentração. Os EUA aparecem no topo do ranking da GCR. Ressalte-se que as duas agências norte-americanas (FTC e DoJ) são classificadas separadamente. A comparação desses dados, sem considerar os orçamentos, evidencia a fragilidade do Brasil, cujo SBDC atua significativamente desaparelhado, tanto em termos de recursos orçamentários como humanos. Esses dados explicam por que o resultado da pesquisa colocou o Brasil numa posição tão desconfortável.

Feitas essas observações, torna-se possível destacar os principais aspectos identificados na pesquisa divulgada pela GCR, que colocou o Sistema de Defesa da Concorrência do Brasil - com uma menção de 2,5 estrelas num máximo de 5 -, na $24^{\text {a }}$ posição, no conjunto das 26 agências de defesa da concorrência avaliadas. Veja Quadro I. 


\section{QUADRO I}

AVALIAÇÃO DAS AGENCIAS ANTITRUSTES - 2004

\section{País}

Classificação (máximo de 5 estrelas)

\begin{tabular}{|c|c|c|}
\hline I & Estados Unidos da América & 4,5 \\
\hline 2 & Alemanha & 4,25 \\
\hline 3 & França & 4 \\
\hline 4 & Holanda & 4 \\
\hline 5 & Itália & 4 \\
\hline 6 & Austrália & 4 \\
\hline 7 & Comunidade Européia & 4 \\
\hline 8 & Nova Zelândia & 4 \\
\hline 9 & Reino Unido & 4 \\
\hline IO & Canadá & 3,75 \\
\hline II & Dinamarca & 3,5 \\
\hline $\mathrm{I} 2$ & Espanha & 3,5 \\
\hline I3 & Finlândia & 3,5 \\
\hline I4 & Irlanda & 3,5 \\
\hline I5 & Suécia & 3,5 \\
\hline 16 & Áustria & 3 \\
\hline I7 & África do Sul & 3 \\
\hline I8 & Coréia do Sul & 3 \\
\hline I9 & Suíça & 3 \\
\hline 20 & Japão & 3 \\
\hline $2 \mathrm{I}$ & México & 2,75 \\
\hline 22 & Israel & 2,75 \\
\hline 23 & Noruega & 2,75 \\
\hline 24 & Brasil & 2,5 \\
\hline 25 & Argentina & $\mathrm{I}, 5$ \\
\hline 26 & Grécia & $\mathrm{I}, 5$ \\
\hline
\end{tabular}

Fonte: Global Competition Review. Disponível em:

<www.globalcompetitionreview.com/news/frontpage.cfm>. Acesso em: ro jul. 2004. 


\section{1 ASPECTOS POSITIVOS APONTADOS PELA PESQUISA}

A pesquisa da GCR registra como relevantes a adoção de diversas ações pelos SBDC em 2003, orientadas para melhorar o combate aos cartéis, e o julgamento de fusões e aquisições, apesar da pouca estrutura que o governo lhes concede. Destacam-se na avaliação as providências inéditas de combate aos cartéis, tomadas pela Secretaria de Direito Econômico, como ações de busca de apreensão de provas na sede de empresas e sindicatos suspeitos e a assinatura do primeiro acordo de leniência do Brasil (no qual a empresa confessa participação num cartel e consegue redução de pena); início de um procedimento simplificado para a análise de fusões e aquisições; e a criação de um site que permite o acesso às informações dos três órgãos do sistema. Na avaliação também foi considerada a independência política nas agências brasileiras, que se mantiveram alheias a pressões políticas e empresariais. As autoridades, por sua vez, estão sendo vistas de maneira mais positiva pelo público e advogados, pelas mudanças, e mostraram disposição para reforçar a atuação.

\subsection{ASPECTOS NEGATIVOS APONTADOS PELA PESQUISA}

Entre os aspectos negativos, a pesquisa indica que a burocracia continua "intensa". O Brasil é visto como um país que pede informações em excesso às empresas antes de julgar as fusões e aquisições. A evolução do sistema brasileiro de defesa da concorrência continua a sofrer pelas "questões irrelevantes" feitas às empresas e pelo quadro "jovem e inexperiente" dos funcionários. A pesquisa observa que a criação de um plano de carreiras no Cade dará mais estrutura e melhores salários, e é vista como necessária para a evolução do sistema de defesa da concorrência.

\section{PRINCIPAIS DECISÕES ADOTADAS PELO CADE NO PERÍODO 1994-2004}

Após a descrição dos principais aspectos apontados pela pesquisa divulgada pela Global Competition Review, procederemos a seguir, de forma sucinta, com vistas a reforçar nossas argumentações, a uma análise sobre o nível de consistência das principais decisões do Cade após a promulgação da Lei Antitruste, em I994. A referida análise foi baseada no exame do instrumental teórico contido nos votos dos conselheiros daquele órgão, em particular dos votos dos conselheiros-relatores, conforme consta no Quadro 2. 


\section{QUADRO 2}

PRINCIPAIS DECISOES ANTITRUSTES ADOTADAS PELO CADE

I994-2004

\section{Caso / Decisão / Resultado}

I. Compra da Siderúrgica Pains pela Gerdau. Decisão: Proibição do negócio. Resultado: O Ministério da Justiça pediu a revisão da decisão e o Cade determinou a venda da Pains a Cabomat.

2. Compra da Kolynos pela Colgate. Decisão: Suspensão da marca Kolynos por quatro anos. Resultado: Criação da marca Sorriso.

3. Fusão da Brahma-Antarctica. Decisão: Venda da marca Bavária. Resultado: A Molson comprou a Bavária e adquiriu em seguida a Kaiser.

4. Acusação de cartel por aumentos nos preços do aço realizado por CSN, Usiminas e Cosipa. Decisão: O Cade multou as siderúrgicas em valor igual a ı\% do faturamento (R\$ 58 milhões, em I999). Resultado: As siderúrgicas recorreram ao Poder Judiciário para não pagar a multa.

5. A Philip Morris acusa a Souza Cruz de impor exclusividade aos postos de venda de cigarros. Decisão: O Cade determina o fim da exclusividade. Resultado: A decisão afeta apenas I\% dos contratos da Souza Cruz com pontos-de-vendas.

6. Compra da Empresa Chocolates Garoto pela Nestlé do Brasil. Decisão: O Cade veta integralmente a compra da empresa Garoto. Resultado: A Nestlé propõe vender as marcas tradicionais e os ativos físicos das duas companhias, que representam ı०\% de "chocolates sob todas as formas", e $20 \%$ do segmento de coberturas. Proposta submetida ao Cade em I6 de abril de 2004. Resultado: A procuradoria-geral do Cade manifestou-se contra a referida proposta. O plenário do Cade ainda não se pronunciou sobre o pedido de revisão da Nestlé.

Fonte: Conselho Administrativo de Defesa Econômica (Cade).

Disponível em: <www.cade.gov.br>. Acesso em: 5 jul. 2004.

Dentre as decisões analisadas, a que tratou do Ato de Concentração no I6/I994, que determinou a desconstituição da compra da Pains pela Gerdau (DUTRA, I999:2I7-454), merece especial destaque. Verifica-se, no referido caso, que o Cade sofreu forte pressão política para alterar sua decisão, que culminou numa interferência indevida do então Ministro da Justiça, que proferiu um despacho avocando o processo, contrariando frontalmente o disposto no artigo $50 \mathrm{da}$ Lei no 8.884/94, que define que "nas decisões do Cade não comportam revisão no âmbito do Poder Executivo". Torna-se possível especular, ainda, diante das evidências - decorridos Io anos daquela decisão emblemática do Colegiado do Cade -, que a lei antitruste foi aplicada de forma correta no referido caso. Além de preservar o interesse dos consumidores, a garantir um mercado de produto 
siderúrgico competitivo, a decisão foi a responsável por colocar o Brasil no elenco de países que, apesar das reconhecidas deficiências do sistema de defesa da concorrência, aplicava com independência sua legislação antitruste (MATIASPEREIRA, 2004b).

Registre-se que os casos julgados no âmbito do Cade geralmente envolvem os interesses de grandes grupos estrangeiros, que estão buscando expandir seus negócios no Brasil. Entre esses segmentos, podemos destacar na atualidade, por exemplo, os de fertilizantes, supermercados e chocolates. As disputas envolvendo um elenco de grandes empresas decorrem das boas perspectivas de ampliação dos negócios dessas companhias no mercado brasileiro (BASILE, 2004). Os indicadores econômicos mostram que o Brasil, entre os países emergentes, é um dos poucos que ainda apresenta oportunidades de negócios que interessam às grandes empresas mundiais. O mercado de chocolate, por exemplo, que se encontra estabilizado nos Estados Unidos (EUA) e na Europa, se enquadra nessa situação, pois vem crescendo $5 \%$ ao ano na América Latina.

Sem embargo, ficou evidenciado nessas análises que, na fundamentação das citadas decisões, foi utilizado um adequado instrumental teórico, tanto na área microeconômica como na do direito antitruste (OLIVEIRA, 200I; OLIVEIRA e RODAS, 2004). Os debates acirrados em torno de todos esses casos, que ficaram restritos aos espaços políticos, empresariais e acadêmicos, e que foram explicitados pela mídia, evidenciam que a sociedade não tem recebido as informações sobre o tema em nível satisfatório. Quando examinamos os reflexos para a sociedade das decisões adotadas no âmbito daquele órgão, do ponto de vista administrativo, jurídico e político, torna-se perceptível que as regras na área da defesa da concorrência, analisadas sob a ótica da mídia, são desconhecidas pela grande maioria da população do país.

Essa percepção é reforçada pela argumentação de Nassif (SALGADO, I997. Prefácio), que destaca que:

falta à mídia, muitas vezes, percepção clara sobre o novo momento, informações sobre funcionamento de economias de mercado, sobre o papel de cada setor e instituição. E, principalmente, valores claros e consolidados. Mas, a cada dia que passa, novos valores vão se consolidando e se incorporando aos usos e costumes nacionais. Em vez de leis, jurisprudências; em vez de regulamentos, conceitos. No plano econômico, poucos temas têm a relevância da questão do abuso do poder econômico.

Assim, torna-se perceptível que o governo não se tem mostrado capaz de informar adequadamente a sociedade da importância das decisões adotadas pelo sistema de defesa da concorrência para o desenvolvimento econômico do país. 
Apesar dessa deficiência, fica evidenciado que a cultura da concorrência se materializa com decisões dessa natureza, conforme constatado pela pesquisa realizada pela Global Competition Review com profissionais que atuam na área.

A complexidade e os interesses empresariais em jogo, que são prejudicados pela burocracia, e o longo tempo despendido nessas análises nos permitem argumentar que é fundamental para o perfeito funcionamento a economia que os atos e as decisões sob a responsabilidade dos órgãos que integram o sistema de defesa da concorrência passem a ter maior celeridade. Essa constatação também está evidenciada na pesquisa realizada pela Global Competition Review em 2002 e 2003 sobre a necessidade de o Estado disponibilizar os recursos necessários - tanto em estrutura como em recursos humanos - para que o órgão possa cumprir adequadamente sua função, incluindo a adoção de um sistema de notificação prévia das operações de fusões (FRANCO NETO et al., 2004). Observa-se, dessa forma, que o Brasil ainda necessita evoluir significativamente no campo da defesa da concorrência.

\section{CONCLUSÕES}

O papel do Estado de orientar e tutelar a liberdade de concorrência e proibir, restringir ou sancionar condutas que atentem de uma forma ilegítima contra ela (POSNER, I998) é essencial para o funcionamento da economia. É dever do Estado dar maior agilidade e tornar mais seletivos os critérios que definem quais atos de concentração precisam ser submetidos à aprovação dos órgãos de defesa da concorrência. Assim, a implementação de medidas para aumentar a articulação entre os órgãos de defesa da concorrência com os demais órgãos de governo nos três níveis, sobretudo com as agências reguladoras de serviços públicos - atividade que faz parte da chamada advocacia da concorrência -, apresentase como uma medida necessária, com vistas a elevar a concorrência e a eliminar distorções que existem nesses setores.

O esquema protecionista, que prevaleceu por várias décadas até o início dos anos 90 do século passado, isolava as empresas da concorrência estrangeira. Isso explica parcialmente por que o tema da defesa da concorrência não tenha chamado a atenção dos governos e dos diferentes agentes econômicos. A ausência de antecedentes sobre a aplicação da legislação de concorrência e, conseqüentemente, a falta de desenvolvimento jurisprudencial e doutrinário sobre o tema é evidente no caso brasileiro (CONSIDERA e CORRÊA, 2002). A carência de uma cultura na área de defesa da concorrência no Brasil explica em parte as pressões e a resistência de setores políticos e empresariais às decisões do Cade.

As pressões políticas e empresariais, que surgem como ações desestabilizadoras do sistema de defesa da concorrência, para tentar rever as decisões do Cade 
em relação às citadas análises, conforme explicitadas pela mídia, foram barradas pela consistência técnica que embasou aquelas decisões. Esses avanços, entretanto, quando analisamos o espaço e o conteúdo das matérias divulgadas pela imprensa, com exceção de artigos escritos por especialistas, que em sua maioria são bastante herméticos, torna-se perceptível que elas não conseguem retratar a importância das decisões adotadas no âmbito do Conselho Administrativo de Defesa Econômica para a sociedade brasileira (NASSIF, I997). Isso requer ações governamentais para informar a sociedade da importância e dos efeitos das decisões tomadas na área de defesa da concorrência para o funcionamento da economia do país.

A mensuração da atuação do SBDC nos últimos dez anos (CADE, 2004) permite-nos sustentar que a consolidação institucional do sistema brasileiro de defesa da concorrência está diretamente relacionada com a qualidade das decisões do órgão na área de fusões e aquisições, que passaram a ser embasadas em análises cada vez mais consistentes (DUTRA, I999; OLIVEIRA e RODAS, 2004). Isso reforça a argumentação de que a preservação das instituições de defesa da concorrência no país passa necessariamente pelo acatamento das decisões daquele órgão.

O Brasil, entre os países em desenvolvimento, se destaca na administração e aplicação das regras de defesa da concorrência (GCR, 2004). Isso é uma realização relevante, especialmente em um país que tem ampla história de intervenção governamental na economia e onde a cultura da concorrência é fraca, tanto na comunidade empresarial como entre a população. À medida que o processo de globalização da economia avança, o Brasil tem de lidar com diversos casos de fusões internacionais envolvendo grandes empresas multinacionais, nos mais distintos setores, como fertilizantes, chocolates, cervejas, aço e saúde, entre outros. É inegável que esses casos têm sido tratados de acordo com os princípios da "melhor prática" identificada na área de defesa da concorrência (CONSIDERA e ARAÚJO, 2002).

Assim, podemos concluir que, numa economia de mercado como a brasileira, o governo e a sociedade organizada devem priorizar o fortalecimento da legislação antitruste e da política de regulação econômica, levando em conta que são dois instrumentos essenciais, que interagem e se complementam, para apoiar o crescimento econômico do país. As manifestações que atentam contra as instituições que tratam desses temas devem merecer maior atenção e reflexão por parte da sociedade, visto que os efeitos dos ataques ao Cade e suas decisões, além de contribuírem para o enfraquecimento institucional dos órgãos governamentais que atuam na área, são prejudiciais à economia e à população, uma vez que desgasta a imagem e a credibilidade das políticas públicas de defesa do consumidor e da concorrência e da regulação econômica do país no mundo. 


\section{REFERÊNCIAS}

BASILE, Juliano. Uma revolução à brasileira pela concorrência. Caderno Valor, São Paulo, n. I75, p. I6-I8, 9-II jan. 2004.

BRASIL. Cade. Decisão do Ato de Concentração que analisou a compra da empresa de chocolates Garoto pela Nestlé. Brasília: Cade/MJ, 2004. Disponível em: <www.cade.org.br>. Acesso em: 25 maio 2004 .

. Ministério da Fazenda (2004). Glossário básico de defesa da concorrência (MF, 2004). Disponível em: <www.fazenda.gov.br/seal/documentos/glossario.htm>. Acesso em: 25 jul. 2004.

BRAULT, D. Droit de la concurrence comparé. Colection Droit des Affaires de L'Entreprise. Paris: Ed. Economica, I995. (Série Recherches).

COASE, R. H. The firm, the market and the law. Chicago: The University of Chicago Press, I988.

. The nature of the firm. Economica, v. 4, p. 386-405, I937.

CONSIDERA, Cláudio M.; ALBUQUERQUE, Kélvia. The relationship between competition policy and regulation brazilian economy. Brasília: Ministério da Fazenda/SEAE, 200I. Working Paper Io, August.

CONSIDERA, Cláudio M.; ARAÚJO, Marina T. Competition advocacy in Brazil - Recent development. Brasília: Ministério da Fazenda/SEAE, 2002. p. I-I2. Disponível em: <www.fazenda.gov.br>. Acesso em: I2 jan. 2004 .

CONSIDERA, Cláudio M.; CORRÊA, Paulo. The political economy of antitrust policy in Brazil - from Price Control to Competition Policy. In: HAWK, Barry E. (Ed.). International antitrust law and policy. New York: Juris Publishing, 200I. p. 533-568. (Annual Proceedings of the Fordham University School of Law).

DAHL, Robert; LINDBOM, C. Politics, economics and welfare. London: Transaction Publishers, I992.

DUTRA, Pedro (Org.). A concentração do poder econômico: Jurisprudência anotada. São Paulo: Renovar, I999. v. I.

FARINA, E. Q. Política industrial e política antitruste: uma proposta de conciliação. Revista do IBRAC, São Paulo, v. 3, n. 8, p. I-I5, I996.

FRANCO NETO, Afonso A. de Mello et al. Nestlé sem Garoto. Folha de S.Paulo, São Paulo, p. A3, 3 mar. 2004.

HODGSON, G. Economics and evolution. Bringing life back into economics. Michigan: The University of Michigan Press, I996.

KAHN, A. E. The economics of regulation: principles and institutions. Cambridge: MIT Press, I988.

KAPLAN, L. Potential competition and section 7 of the clayton Act. The Antitrust Bulletin, v. XXV, n. 2, I980.

KWOKA, J.; WHITE, L. (Eds.). The antitrust revolution - economics, competition and policy. 3. ed. Oxford: Oxford University Press, I999.

MACNEIL, I. R. Contracts: adjustment of long-term economic relations under classical, neoclassical, and relational contract law. Northwestern University Law Review, n. 72, p. 854-906, I978.

The many futures of contracts. California Law Review, v. 47, p. 691-8I6, I974. 
MATIAS-PEREIRA, J. Economia brasileira. São Paulo: Atlas, 2003.

Políticas públicas de defesa do consumidor e da concorrência no Brasil: uma avaliação do processo de consolidação institucional do sistema brasileiro de defesa da concorrência. Revista Académica de Economía, Málaga, n. 24, p. I-15, mayo 2004.

NASSIF, Luis. Prefácio. In: SALGADO, Lúcia H. A economia política da ação antitruste. São Paulo: Singular, I997.

NORTH, D. Estructura y cambio en la historia económica. Madrid: Alianza Universidad, I984. Economic performance through time. American Economic Review, v. 84, n. 3, p. 359-368, June I994.

Institutions, institutional change and economic performance. Cambridge: Cambridge University Press, I990.

OCDE. Regulatory reform, privatization and competition policy. Paris, I992. Disponível em: <www.oecd.org>. Acesso em: I2 abr. 2004.

OLIVEIRA, G. Concorrência - panorama no Brasil e no mundo. São Paulo: Saraiva, 200 I.

OLIVEIRA, G.; RODAS, João G. Direito e economia da concorrência. São Paulo: Renovar, 2004.

OLSON, M. The rise and decline of nations. New Haven: Yale University Press, I982.

POSNER, R. Economic analysis of law. 5. ed. Asper Law \& Business, I998.

POSSAS, M. Os conceitos de mercado relevantes e de poder de mercado no âmbito da defesa da concorrência. Revista do IBRAC, v. 3, n. 5, I996.

POSSAS, M.; FAGUNDES, J.; PONDÉ, J. Política antitruste: um enfoque schumpeteriano. Anais do XXIII Encontro nacional de economia. Salvador: ANPEC, I995.

ROSS, S. A. The economic theory of agency: the principal's problem. American Economic Review, n. 63, p. I34-139, I973. Papers and Proceedings.

Principles of antitrust law. New York: The Foundation Press, I993.

SAFATLE, Claudia. Agência de defesa da concorrência atrasa. Valor Econômico, São Paulo, p. A2, 27-29 fev. 2004 .

SALGADO, Lúcia H. A economia política da ação antitruste. São Paulo: Singular, I997.

SIMON, H. A. Theories of bounded rationality. In: MCGUIRE, C. B.; RADNER, R. (Eds.). Decision and organization. New York: American Elsevier, I972.

STIGLITZ et al. The economic role of the state. Oxford: Basil Blackweel, I990.

SULLIVAN, E.; HARRISON, J. Understanding antitrust and its economic implications. New York: Matthew Bender \& Co, I988.

WILLIAMSON, O. The economic institutions of capitalism. New York: The Free Press, I985.

The mechanisms of governance. Oxford: Oxford University Press, I996.

TRA M ITAÇÃ O

Recebido em 28/04/2004

Aceito em 16/08/2004 
Copyright of Revista de Administração Mackenzie is the property of Universidade Presbiteriana Mackenzie, RAM-Revista de Administracao Mackenzie and its content may not be copied or emailed to multiple sites or posted to a listserv without the copyright holder's express written permission. However, users may print, download, or email articles for individual use. 